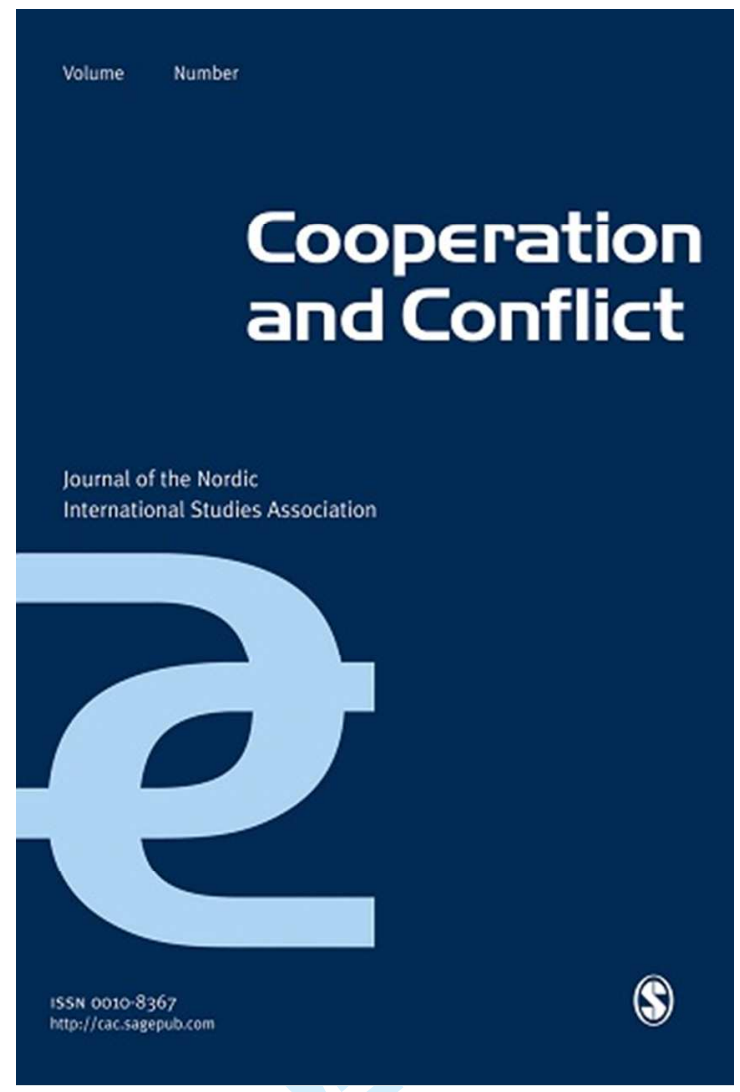

\title{
National security risks? Uncertainty, austerity and other logics of risk in the UK government's national security strategy
}

\begin{tabular}{|r|l|}
\hline Journal: & Cooperation and Conflict \\
\hline Manuscript ID: & CAC-13-0003.R1 \\
\hline Manuscript Type: & Original Article \\
\hline Keywords: & $\begin{array}{l}\text { concept of security, risk, securitisation, discourse analysis, UK, national } \\
\text { security strategy }\end{array}$ \\
\hline Abstract: & $\begin{array}{l}\text { Risk scholars within Security studies have argued that the concept of } \\
\text { security has gone through a fundamental transformation away from a } \\
\text { threat-based conceptualisation of defence, urgency and exceptionality to } \\
\text { one of preparedness, precautions and prevention of future risks, some of } \\
\text { and how the concept of security is changing due to this 'rise of risk', } \\
\text { through a hermeneutically grounded conceptual and discourse analysis of } \\
\text { the United Kingdom government's national security strategy (NSS) from } \\
1998 \text { to } 2011 . \text { We ask how risk-security language is employed in the NSS; } \\
\text { what factors motivate such discursive shifts; and what, if any, }\end{array}$ \\
\hline
\end{tabular}


2

3

4

5

6

consequences of these shifts can be discerned in UK national security practices. Our aim is twofold: to better understand shifts in the security understandings and policies of UK authorities; and to contribute to the conceptual debate on the significance of the rise of risk as a component of the concept of security.

SCHOLARONE ${ }^{\text {m }}$

Manuscripts 


\title{
National security risks? Uncertainty, austerity and other logics of risk in the UK government's national security strategy
}

\author{
Of course, in an age of uncertainty the unexpected will happen, and we must be prepared to \\ react to that by making our institutions and infrastructure as resilient as we possibly can. ${ }^{1}$
}

\begin{abstract}
This quote from the introduction to the UK government's 2010 National Security Strategy (NSS) document presented to Parliament, seems to confirm a recent contention by many security analysts: For policy makers, security has become less about the defence against known and specific threats. It is instead about precautions against and - when possible - prevention of future risks, some of which are calculable, others of which are not. Risk scholars within Security Studies have suggested that '[r]isk and uncertainty are the hallmarks of world politics at the dawn of the twenty-first century' (Williams, 2008: 58). Security practice no longer takes place within the Cold War paradigm of deterrence and defence, but follows the precautionary principle, where it is worth acting today because the possibility of catastrophe in the future is so calamitous that we cannot risk inaction.
\end{abstract}

Individual quotes, such as the one above, may be striking, but are not necessarily symptomatic of deeper shifts in conceptualisations of security. In this article we investigate the extent to which the national security thinking behind the formulation of the United Kingdom's national security strategy (NSS) from 1998 to 2011 has taken on a language and logic of 'security risks'. We ask how risk-security language has been employed in the NSS; what the factors are that motivate such discursive shifts; and what, if any, consequences of these shifts can be discerned in UK national security practices. Our aim is twofold: to better understand shifts in the security understandings and policies of UK authorities; and to contribute to the conceptual debate on the 1

http://mc.manuscriptcentral.com/cac 
significance of the rise of risk as a component of the concept of security. While anchoring our investigation in discourse and conceptual analysis, we relate these findings hermeneutically to (perceived) changes in the security environment and in security policies and practices.

We begin the article by discussing this methodological approach. Based on the work of Petersen (2013), we then identify three 'schools' of risk-security analysis in IR: 'Risk as governmentality' and 'global risk management' are both drawn from sociology; while the third school, 'political risk analysis', is adapted from economics and business studies. The main body of the article is our discourse analysis of the UK's national security strategy (NSS). The concluding section then reviews our findings in terms of the conceptual, practical and normative tenets of the three risksecurity schools. We suggest that the relative rise of risk in the NSS is significant, but does not yet - amount to a dramatic reconceptualisation of the concept of security among UK security policy makers.

\section{A discursive and conceptual approach}

We have chosen to centre our analysis on the discursive and conceptual level, rather than on security practices or context. While both the latter are highly significant, we do this for three reasons: First, it is useful to conduct systematic, in-depth empirical research on the nature and trajectory of 'the rise of risk' in the conceptualisations of security held by state security elites. Findings from such empirical research feed into theoretical debates on how political concepts such as 'security' can and do change. The meaning of the concept of security is not objectively defined but reflexive and constructed, and the answer to the question 'what is security' is worked out through political debate and embedded in historical and social traditions (Freeden, 1996: 5253). An important part of security research - and indeed security theorising - must therefore be to study what, actually, security practitioners make of security in particular contexts. Following 
Ciuta (2009: 325-325), this article is an effort at 'taking seriously the definitions and practices of actors'.

Second, and deeply connected to the first point, we wanted to do more than provide a snapshot of the official security discourse of the UK government. We study the core NSS documents from 1998 to 2011, to see not only how the concept of risk has been introduced, but also how its usage has changed and become more prominent over time. This enables us to reflect on how the concept of security is changing, and hence contribute to the long-standing Security Studies debate on the nature and durability of the concept of security.

Petersen (2012: 708) argues that neither 'risk nor security alone can be considered an analytical or theoretical concept'. This may be true about 'risk', but 'security' has a long history as a core political concept in philosophical and public debates on how to organise political communities. The question is not whether 'risk' is replacing 'security', but whether 'risk' is becoming an increasingly central and accepted component of contemporary conceptualisations of security. As is the case with all political concepts, the meaning of 'security' is never fixed and immutable. Political concepts are 'constructs that reflect social and historical usage' (Freeden, 1996: 52). This means the contents of the concept of security can change over time and across audiences, but not arbitrarily. When interpretations of the meaning of security change, they do so within the confines of what is intelligible and acceptable within the social, cultural and historical parameters of a particular time and place. Otherwise, the new interpretation is unlikely to take hold beyond academic debates (Hammerstad, 2014: 22).

The debate on risk in the International Relations literature has, in the view of Petersen (2012), been limited in comparison to that taking place in the field of sociology. She argues that 'risk studies within security studies cling to the very generalized descriptions of current social 3 
developments and trends; description such as "risk society", "culture of fear" or "risk/security dispositifs" which tends to conceal a possibly much greater variety of conceptual understandings in the daily practices of security agents' (Petersen, 2012: 696). The discourse analysis in this article provides an opportunity to move beyond generalisations about security in an 'era of uncertainty', and discover the nuanced and differing ways in which 'risk' is employed in the UK government's NSS. Some usages are mundane; others are transformative. The language of risk serves rhetorical purposes, but also reveals shifts in security elites' perception of the nature of the UK's external security environment.

This leads us to our third reason for focusing on discourse: discursive shifts are significant. By mapping discursive changes, we discern changes in the mental landscapes of security analysts and practitioners; changes in perceptions of what is deemed natural, convincing, possible, proper, necessary and desirable. How we think about security affect how we formulate security strategies, enact security policies, and even chose rhetorical tools. Security practices and changes in the material environment in turn affect discursive changes, in an hermeneutical circle between horizon, perception and practice. While our analysis centres on the discursive level, we relate our findings to changes in security practices and the external environment, in order to better understand not just how, but why, conceptualisations of security change, and what impact such changes have.

\section{Three risk schools}

Before embarking on an analysis of the UK government's national security strategy discourse, we briefly recount the academic discussion on the meaning and significance of the rise of risk. A risk approach has developed partially as a challenge to what has become the most dominant constructivist security approach, the Copenhagen School. In brief, the Copenhagen School 
based its original formulation of securitisation theory on a traditional conception of security revolving around notions of existential threat, survival, confrontation and competition. It maintains that a securitised issue acquires the logic of security; it becomes subsumed within a politics of survival and urgency that justifies exceptional measures to counteract the perceived threat (Buzan et al, 1998).

Risk scholars dispute the zero-sum, existential logic of the Copenhagen School's conceptualisation of security: 'risk-security writers are not suggesting an adjustment to the conventional notion of security but a radical reconfiguration of the concept itself (Corry, 2010: 10). They propose 'risk' as 'the master concept' of security (Corry, 2012: 243), in contrast to 'threat' as representing the Copenhagen School. For most risk scholars, the rise of risk requires a new security logic. Unlike threats, which are discrete and tangible, risks are everywhere, but only as possibilities. 'Global risks make us insecure because they have become endless, too large and too apocalyptic to be contained within regimes or new world orders' (Coker, 2002: 59). A risk perspective on security differs from the Copenhagen School in that it is concerned with systemic characteristics rather than the intentions and actions of (enemy) actors (Aradau et al, 2008: 148). Risk language tends to 'depersonalise danger': One can trace no clear enemy as so many aspects of society may be defined in terms of risk (Aradau et al, 2008: 151; Corry, 2012: 244; Salter, 2008; Van Munster, 2005: 6-7). The language of risk does not posit direct causal patterns between threats and referent objects, but highlights, in Kantian terminology, 'the conditions of possibility' wherein a risk could transform into actual harm.

But it is not enough to contrast risk scholars to the Copenhagen School. There are (at least) three different 'risk schools' within Security Studies (Petersen, 2012: 701-708), with different methodologies and normative agendas. First, the 'risk as governmentality' school is concerned with transforming the concept of security from war and violence to governance and technology, 5 
taking their cue from sociological governmentality approaches and the works of Foucault. ${ }^{2} \mathrm{~A}$ second school, 'global risk management', also views the concept of risk as transformatory. This group is inspired by Beck's and Giddens' macro-sociological and historical analyses of societal transformation 'from security and nation state to risk and globalization' (Petersen, 2012: 703). Unlike threats, risks are unforeseen and unpredictable (at least in their particular instances), and living with risk is a permanent feature of society (Beck, 1992, 1999). Hence, 'identifying an existential threat would no longer be a necessary part of securitisation if potential risks rather than actual threats dominate the political security imagination' (Corry, 2012: 243, emphasis in original; Elbe, 2008: 179). When risks are viewed as 'too large and too apocalyptic', the precautionary principle sets in: Taking action now to avoid a possible future catastrophe. Williams (2008: 74) argues that '[i]ncreasingly, precautionary action will be a driver of security policy with profound implications for international relations'.

The third school, 'political risk analysis', is less ambitious in theoretical reach, but purports to be scientific, in the positivist sense, in its methodology. It does not try to understand the conditions of late modernity or the neoliberal power structures underpinning governmentality, but is a 'problem-solving' method for assessing 'political risks' such as war, political violence, terrorism, or expropriation of private property (Petersen, 2012: 705). Inspired by business studies and economic theory, political risk analysts are concerned with the actuarial logic of risk-security, a logic more commonly associated with the insurance industry than security practitioners. Setting the security agenda becomes synonymous with assessing risks through the identification of risk groups and risk factors, using statistics, scenario-building and other tools to measure risk probability and severity.

The three risk schools differ in their view on how risk-security logic manifest in security practice. The global risk management school, inspired by Beck's Risk Society (Beck, 1992, 1999) tends 6 
towards an optimistic view of security policy. They see possibilities for collaborative security practices, wherein states and societies work constructively together today to prevent possible disastrous events in the future. Prevention, in the form of dialogue, collaboration, adaptation, resilience, legitimacy, and enhancement of governance capacity, can transform security politics away from confrontation and conflict (Corry, 2012; Trombetta, 2008). Steinbrunner (quoted in Coker, 2002: 54) argues that 'one of the most fundamental implications of globalisation is the shift in the balance of reliance in security policy from deterrence to reassurance and from active confrontation to cooperative agreement'.

But prevention can also assume a confrontational hue, including pre-emptive strikes (Aradau and Van Munster, 2007; Coker, 2002; Heng, 2006; Van Munster, 2005; Williams, 2008). This is sometimes pointed out by global risk management scholars, but is more often the topic of the governmentality school. Inspired by Foucault's writings on biopolitics, power and control, they emphasise the pernicious quality of security politics even within a risk-security logic. They understand risk-security practices as every-day bureaucratic routines of monitoring and control. When security is about risk management, it becomes a matter of long-term governance and routine procedures aimed at controlling uncertainty (Corry, 2012: 245, 247; Salter, 2008; Van Munster, 2005). '[R]isk is a social technology by means of which the uncertain future, be it of a catastrophic nature, is rendered knowable and actionable' (Aradau et al, 2008: 150). Actions are taken to mitigate uncertainty and control risk - or at least to be seen to control risk by 'doing something'. Such actions could include building climate change scenarios; surveillance practices and border security measures to control undocumented immigration; or 'risk profiling' of, and targeted measures towards, 'risk groups' considered particularly likely to commit terrorist acts or spread communicable diseases (Aradau and Van Munster, 2007: 100; Elbe, 2008: 180). 
The political risk school has a more managerial outlook than the other two. It aims to develop methods with which to measure the likelihood and impact of a particular risk occurring. Such risk analysis has long been conducted on behalf of companies seeking to invest in the developing world. More recently, it has been taken on by state security policy makers, for example in the UK's pioneering National Risk Assessment (NRA), launched in 2008. This classified document, together with its publicly available sister publication, the National Risk Register (Cabinet Office, 2012), covers risks and mitigation strategies for 'natural events, major accidents and malicious attacks' on the country's territory, people and infrastructure.

Risk assessment exercises such as the NRA, conducted in the spirit of the political risk analysis school, are pursued by authorities as a tool with which to prepare themselves and their societies for the future. They can reduce the risk of calamities through prevention, or if that cannot be done (e.g. in the case of natural disasters), then at least reduce the destructive impact of such calamities, through resilience building and disaster management planning. As can be gleaned from the earlier discusssion of the governmentality approach, Foucauldian risk scholars view such 'problem-solving' risk analysis exercises in a less positive light. They argue that the governmentality of creating societies resilient to risks is yet another, stealthy and expansive, way in which governments work to control populations. The logic of precautionary risk works so that concern over countless but unknowable catastrophic risks leads to '[p]rofiling and surveillance encompass[ing] the whole population' and 'everybody [becomes] regimented into technologies of vigilance and prudentialism' (Aradau and Van Munster, 2007: 107).

Joseph (2011) sees the rise of 'resilience' - a corollary of risk - as yet another cog in neoliberal governmentality, where security is individualised and privatised. In the UK, commuters are urged to look out for suspicious individuals and packets on public transport, while landlords and employers are asked to report suspected undocumented immigrants to the authorities. 8 
Everybody is tasked with building 'resilience' in the face of ever-longer lists of risks. The provision of security is no longer the prerogative of national security elites, but can be outsourced to companies, local government and individual citizens.

As we turn to a discourse analysis of the UK government's national security strategy (NSS), we will examine how the usages of risk-language correspond to the normative and methodological assumptions of the three risk schools described above. Does the risk-language of the NSS mostly belong in the 'political risk analysis' school, in that it tries to make security policy-making grounded in positivistic, 'scientific' and rational probability and cost-benefit analyses? Or is it transformative in the sense of seeking to build institutions and processes to foster longer-term, co-operative, global or local risk management, and thereby to overcome the competitive us-them threat language of traditional conceptualisations of security? Or is the language of risk-security in the NSS, and the practices it legitimises, best understood from the point of view of the power structures it serves and enhances, in that it expands the ability of local or national authorities to regulate, control, survey and render ever larger groups of individuals or sets of behaviour as 'risky'?

\section{The UK government's national security discourse}

In this discourse analysis of the UK government's NSS from 1998 to 2011, we review all MOD strategic defence reviews and Cabinet Office national security strategies, starting with the Strategic Defence Review (MOD, 1998). We also include documents covering security broadly speaking from the MOD's Development, Concepts and Doctrine Centre (DCDC), and one joint document from the Department for International Development (DfID), Foreign and Commonwealth Office (FCO) and MOD. 
Informed by the work of Freeden (1996) on political concepts, we employ discourse analysis in the practical manner of identifying core terms within the NSS texts, tracing when they appear, how they evolve over time, how they congregate and relate to each other, and which are core to the discourse and which are more peripheral. We pay particular attention to the role the terms of 'threat' and 'risk' play within the concept of security, and how these terms are used in justifications of particular security prioritisations and policies. The analysis categorises the grammar of threat as linked with confrontation, aggression, enemy, urgency, direct and acute threats, elimination, and defence. The grammar of risk includes uncertainty, future challenges, possibility, potentiality, management, mitigation, resilience, governance, calculation and prevention.

The usage of risk-security langauge in the NSS documents from 1998 to 2011 can be divided into four clusters. First, it covers potentiality, future challenges, uncertainty and unknown/unquantifiable dangers. Second, it is prominent in discussions of remote security issues, not posing an immediate danger to the UK or its national interests. Third, it promotes societal resilience and 'preparedness'. Finally, it flourishes in the context of budget cuts and austerity measures, where risk assessments are used as a 'scientific' method for determining cuts and priorities. We discuss each cluster before addressing a topic notable for its lack of prominent risk language: The discourse on international terrorism is permeated by the language of threat. Since terrorism has been highlighted in the risk-security literature as driven by the logic of risk, this finding warrants a separate discussion.

\section{Risk and the unknown}

The NSS documents usually present future potential security challenges, such as climate change, pandemic diseases, and migration/demography, as risks. ${ }^{3}$ In contrast, issues such as terrorism 
and organised crime, whose damaging impacts are seen to have already begun to materialise, are largely depicted as (clear and present) threats. ${ }^{4}$

Concern with uncertainty, probabilities and risks, rather than actualities and threats, is widespread in the NSS. Most of the documents begin by asserting that we live in an 'era of uncertainty', as opposed to an earlier period when life was more predictable. For instance, the 1998 Strategic Defence Review announces that a new era has set in, where 'there is no longer a direct threat to Western Europe or the United Kingdom as we used to know it, and we face no significant military threat to any of our Overseas Territories' (MOD, 1998: chapter 2:21). Yet, this does not make us more secure than before. The new era is portrayed as littered with new and potentially catastrophic challenges with a high degree of uncertainty, such as environmental change and cyber attacks.

The earliest of the documents we analyse often uses 'risk' and 'threat' interchangeably. It frequently refers to new risks as threats and uses traditional security language of danger and attack to describe them: 'There are [...] new risks which threaten our security by attacking our way of life.' (MOD, 1998: chapter 1:9). This muddle could be seen to undermine risk scholars' assertion that the language of risk creates a new security grammar. However, when viewing the NSS documents chronologically, it is more accurate to see it as a sign that in 1998 risk-security language was just emerging, enthusiastically embraced by, but not yet securely established in the NSS discourse.

The message of a fast-changing and uncertain security landscape is recurrent throughout the period studied. The 2010 National Security Strategy (Cabinet Office, 2010a) presents the clearest distinction between 'risk' and 'threat'. The document is littered with the core risk-security terminology such as uncertainty, vulnerability, resilience, flexibility and preparedness. Despite 11 
this, the discourse is anchored in a traditional security rationale. The Foreword presents a security message of threats and enemies, asserting that: 'This Strategy is about gearing Britain up for this new age of uncertainty - weighing up the threats we face, and preparing to deal with them'. (Cabinet Office, 2010a: 3)

It is noteworthy that the concept of threat dominates the forewords to both the two 2010 national security strategy documents, while the documents' main bodies employ a more even mix of 'threat' and 'risk' language (Cabinet Office, 2010a, 2010b). The more urgent and dangerous sounding 'threat' seems to be chosen when the aim is to grasp attention and establish the pressing nature of the document's message. Risk language is then built on top of this threat rationale, for instance by presenting preventive security strategies: 'we are going to place much more emphasis on spotting emerging risks and dealing with them before they become crises' (Cabinet Office, 2010a: 5).

The topic of Weapons of Mass Destruction (WMDs) exemplifies the different purposes 'risk' and 'threat' serve in the NSS discourse. 'Risk' tends to be employed when discussing WMDs as potentialities, and possible scenarios of nuclear confrontation. ${ }^{5}$ 'Threat' is generally used when discussing WMDs as direct or proximate threats to the UK; $;^{6}$ traditional military options such as armed response and deterrence; $;^{7}$ or WMDs and international terrorist networks. ${ }^{8}$ This confirms risk scholars' argument that risk language is distinct from that of the Copenhagen School terminology. The former is about managing conditions of possibility, while the latter invokes immediacy. Both are eminently present in the discussion of WMDs.

\section{Far-away risks, proximate threats}

Traditional security issues, such as armed conflict, are mostly discussed through a language of threat. One exception is when addressing the need to 'prevent, mediate and mitigate' distant 
conflicts and instability (Cabinet Office, 2008: 13-14, 33-41, 2010b; DFID, FCO and MOD, 2011; JDCC, 2003: 7-21). While conflict overseas is a traditional politico-military security matter, risk language is allowed to dominate discussions of conflict in far-away parts of the world as long as preventing or intervening in such conflicts are not presented as vital to the UK's own security. Building stability overseas is argued to be in Britain's interest, as it may lead to a spread of Britain's democratic values. It is also presented as cost-effective, since prevention is cheaper than humanitarian (military) intervention (DFID, FCO and MOD, 2011: 4). As soon as the discussion turns to the danger of direct harm to the UK, for instance failed states becoming safe havens for international terrorists, the language of threat usually reappears. ${ }^{9}$

Risk language gives the UK government a greater range of options for how to respond to instability and conflict in distant (geographically and/or politically) parts of the world. Threats demand a response. Risks can be weighed, and according to the logic of the political risk school, calculations of the probability of a conflict happening, and of it affecting UK interests, can be made. As an example of such a strategy, the UK Stabilisation Unit has developed a conflict assessment tool focussed on prevention, called the Joint Assessment on Conflict and Stability (JACS). This tool aims to monitor fragile states that are not top national security priorities, but should be kept 'on the horizon to prevent conflict from arising'. ${ }^{10}$

Since such calculations inevitably depend on assumptions, selections and omissions based on analytical outlook, historical lessons and partial empirical knowledge, there is significant room for choice regarding if and how the UK should become involved in particular conflicts overseas. Thus, reliance on the language of risk can make security responses less prescriptive and thus less predictable. The 2010 NSS documents' lack of prescriptive authority was criticised by the Parliamentary Joint Committee on the National Security Strategy (2012: 16). The committee commented: "We accept that the NSS is not a "recipe book" which dictates our response to 13 
every event, but we would have expected to have seen some evidence that it had influenced decisions made since the SDSR [Strategic Defence and Security Review], including the Government's responses to the Arab Spring [for instance to intervene militarily in Libya but not in Syria]. We have found no such evidence.'

\section{Resilience, preparedness and proactive security}

In the case of non-traditional security issues such as climate change or pandemic diseases, the NSS documents generally suggest 'soft' security responses. Rather than conjuring up images of hostility and confrontation, the language of risk is employed to outline strategies 'to prevent emergencies arising in the first place' (Cabinet Office, 2008: 41) and find 'collective solutions' and 'opportunities for international cooperation' (Cabinet Office, 2008: 18; 2010a: 20). The use of risk language often signifies an optimistic view of security, geared towards working together to reduce risks and build a more secure future for all. These findings are in line with the global risk management school's assertion of risk-security's transformative quality, triggering a security practice of management and coping, rather than elimination and defence. For example, in the area of climate change, the FCO has made active use of security language to endorse greater preventive climate action amongst states. This illustrates how softer notions of security can coincide with alternative security practices of prevention and diplomacy (Trombetta, 2008). As argued by Margaret Beckett, UK Foreign Secretary in 2006-2007:

\footnotetext{
[W] hile an unstable climate has obvious hard security implications, the traditional tools of hard security - in simple terms bombs and bullets - are not going to solve that problem. Instead we are going to have to think a lot more imaginatively and a lot more broadly about how we can act together to guarantee that kind of security. And that will mean much greater understanding of and commitment to non-military options: to international diplomacy; to leveraging
} 
international finance and markets; to building coalitions between governments, business and consumers (Beckett, 2007).

The FCO involved the military in executing this form of preventive diplomacy when appointing Rear Admiral Neil Morisetti as UK Climate and Energy Security Envoy. The position, tasked with raising awareness of the urgency of mitigation action to prevent a dangerous scenario of climate change (FCO, 2010: 21), was discontinued at the end of 2012.

In an 'age of uncertainty' where not all risks can be eliminated, the flip side of precaution is resilience - the ability to bounce back when disaster strikes. '[W] cannot prevent every risk as they are inherently unpredictable. To ensure we are able to recover quickly when risks turn into actual damage to our interests, we have to promote resilience, both locally and nationally' (Cabinet Office, 2010a: 25). Hence, in recent years the NSS discourse has included the theme of strengthening the resilience of UK society faced with various disasters from floods and pandemics to terror attacks and organised crime. ${ }^{11}$ These ideas are already being implemented through the UK's National Risk Assessment (NRA) and National Risk Register, exercises that are deeply in the mould of the positivistic political risk school. The governmentality school, however, views such developments with some reservation, as it redirects responsibility for security from the state to the individual (Joseph, 2011). To ensure the UK's own national security, UK citizens are asked to 'look after themselves and each other for a period until any necessary external assistance can be provided' (Cabinet Office, 2011: 3).

\section{Budget cuts and security choices}

Risk language reached particular prominence in the NSS discourse in the wake of the global financial crisis. Risk language is employed to make the realm of security politics calculable and 
controllable - or at least seemingly so - through risk assessment exercises, statistical prognosis and scenario building. Such exercises are common in recent NSS documents for the specific purpose of justifying budget cuts in national security spending.

The two main NSS documents in 2010 utilise a 'National Security Risk Assessment' to determine and justify tough security policy choices (Cabinet Office, 2010a, 2010b). The risk assessment follows the positivist ambitions of the political risk analysis school in attempting to identify risks in terms of probability and impact, and use these 'calculations' to present a cost-effective security strategy built on a hierarchy of Tier One, Tier Two, and Tier Three risks: 'In particular, it helps us to prioritise the risks which represent the most pressing security concerns in order to identify the actions and resources needed to deliver our responses to those risks' (Cabinet Office, 2010a: 25-27). The dramatic budget cuts themselves were presented as a security issue:

\footnotetext{
'Our ability to meet these current and future threats depends crucially on tackling the budget deficit. Our national security depends on our economic security and vice versa [...]. So at the heart of the Strategic Defence and Security Review are some tough choices to bring the defence budget back to balance. Those choices are informed by the risks, analysis and prioritisation set out in this National Security Strategy'. (Cabinet Office, 2010a: 4)
}

Similarly, the recent focus on soft security tools such as prevention, risk management and diplomacy flows to some extent from budget concerns:

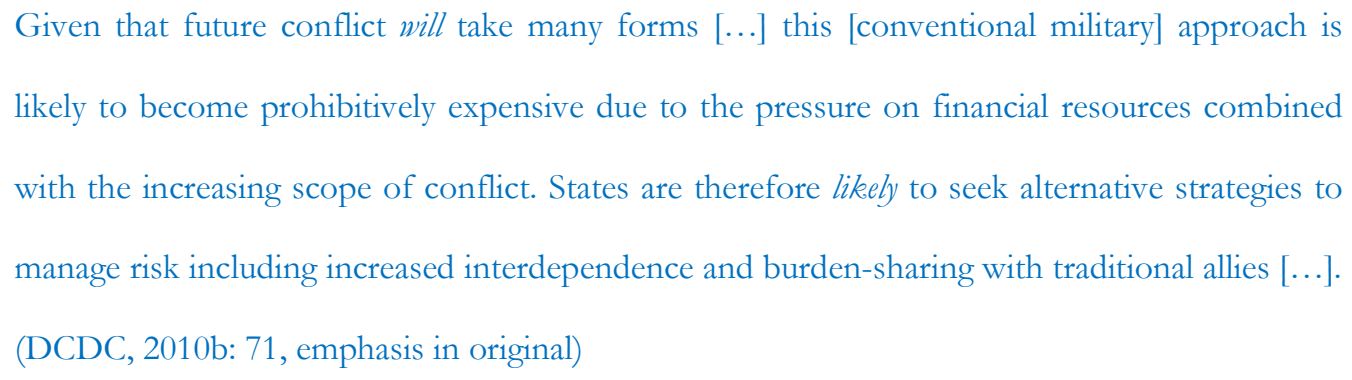


The DCDC stresses (although with some contradictions and caveats) that preventive strategies are 'better and cheaper than cure' (DCDC, 2010a: 36) and that ' $£$ 1 spent on conflict prevention generates over $f^{4}$ in savings for the international community' (DCDC, 2010a: 27; see also Cabinet Office, 2010b: 3; DFID, FCO and MOD, 2011: 4).

Risk language suits the austerity message of the recent NSS discourse well. Adopting a financial language of quantification and prioritisation, the National Security Risk Assessment aims to justify hard choices with scientific reasoning to reassure citizens that the government remains capable of responding to both financial and security challenges.

\section{Terror threats}

Soon after 11 September 2001, Rasmussen (2001: 308) argued that the terror attacks on the US were 'a tragic example of a new asymmetrical strategic reality that is better understood by the concept of risk society than by traditional notions of terrorism'. Several risk scholars have highlighted counter-terror as guided by risk-security logic (Aradau and Van Munster, 2007; de Goede, 2008; Mythen and Walklate, 2008; Rasmussen, 2004; Van Munster, 2005). A more nuanced picture emerges from an analysis of the terrorism discourse in the NSS.

Before 2001, the NSS discourse presented international terrorism as one among several potential risks: 'over the next twenty years, the risks to international stability seem as likely to come from other factors [than state aggression]: ethnic and religious conflict, population and environmental pressures; competition for scarce resources; drugs, terrorism and crime' (MOD, 1998: chapter 2:29). In contrast, from 2002, the NSS discourse largely portrays terrorism in traditional security language of deterrence, threat and enemies. Resolved to 'look again at the United Kingdom's defence posture and plans to ensure that we have the right concepts, the right capabilities and 17 
the right forces to meet additional challenges we now face', the 2002 NSS document (MOD, 2002a: 6) functioned as a securitising act, using traditional security language to justify additional spending and draconian measures to counter the terror threat. The document uses aggressive language such as 'eliminate terrorism', 'enemies', 'aggressors', 'deter' and 'defeat international terrorism', and argues that '[w]e must [...] continue to be ready and willing to deploy significant forces overseas, and, when legally justified, to act against terrorists and those who harbour them' (MOD, 2002a: 9).

While prevention can be part of the risk vocabulary, it can also justify pre-emptive strikes: 'the main sorts of military effect we can bring to bear are to prevent, deter, coerce, disrupt or destroy our opponents', whether international terrorist organisations or the states that sponsor them (MOD, 2002a: 9). In a similarly confrontational vein, the MOD argues that ' $[w]$ e must influence leaderships [of 'states of concern and terrorist organisations'] by showing that we are prepared to take all necessary means to defend ourselves' (MOD, 2002a: 12).

In 2008, international terrorism (described as a 'new' risk in 1998) is referred to as one of the 'more traditional security threats' (Cabinet Office, 2008: 4). The document stresses that '[t]he threat of terrorism is real and $[\ldots]$ more serious than those we have faced in the past', although it places less emphasis on military capabilities, and more on intelligence, police work and cooperation with other governmental and private sector actors, than the 2002 document (Cabinet Office, 2008: 25-28). Chapter three, entitled 'Security challenges', leads with a section on terrorism which is void of risk-security terminology, while a later section on infectious diseases and extreme weather events is dominated by risk language (Cabinet Office, 2008: 10-11, 14-15). There seems to have been a deliberate choice to describe terrorism in traditional security language, setting it apart as the most urgent security challenge facing Britain. 
To some extent risk language has reappeared in the terrorism discourse in the 2010 NSS, which discusses terrorism under the headings 'highest priority risks' (Cabinet Office, 2010a: 28) and 'Tier One risks' (Cabinet Office, 2010b: 41). Nonetheless, the actual discussion of terrorism beneath such headings is steeped in threat-security formulations such as ' $[\mathrm{t}]$ he current threat to the UK from international terrorism is judged to be Severe, meaning that an attack in this country is highly likely' (Cabinet Office, 2010b: 41). The headings are determined by the National Security Risk Assessment, which provides an overall framework for the 2010 NSS. Within this framework terrorism is a Tier One risk, but the main purpose of the framework itself is, as discussed, to justify austerity measures (Cabinet Office, 2010a: 13-14, 16, 28-20, 2010b: 4144).

Aradau and Van Munster (2007: 107-8) argue 'that the "war on terror" should be understood through the prism of precautionary risk rather than the traditional theoretical lenses of IR'. Our analysis of the NSS suggests a need to modify this. Certainly a host of anti-terror security practices in the UK follow the precautionary principle - including heightened surveillance, risk screening, participation in rendition processes of 'high-risk' individuals, and detention without trial. But such practices are predominantly legitimised through a discourse of direct and urgent threat, not risk.

\section{Conclusion: risks and threats}

Some risk scholars argue that a transition to the concept of risk has led to a fundamental redefinition of security away from its traditional meaning in International Relations as the protection of highly valued goods against threats to their destruction. Our analysis shows the 'rise of risk' in the NSS to be less a matter of fundamental transition and more an embellishment and expansion of the concept of security. The traditional threat-security conceptualisation remains dominant when the UK government aims to convince its audience of the need to 19 
prioritise a particular security issue, such as terrorism. In this sense, the Copenhagen School's understanding of 'securitising acts', and how and why they are performed, corresponds with the use of threat language in the NSS.

But this is only part of the story. Risk language has obtained a significant role, particularly within the 2010 NSS. Risk and its adjoining terms serve two important purposes in the NSS. First, it facilitates expansion of security policy into new areas such as climate change, and when addressing distant conflicts and instability. Second, and somewhat opposite, it provides a 'scientific' justification for defence cuts and hard choices in a time of austerity.

The NSS authors often seem at home in the 'political risk' school. In the years after the global economic crisis in 2008, present and certain economic woes pulled rank on future security uncertainties in the calculations of security officials, leading to a particularly actuarial conceptualisation of risk as cost-benefit analysis to justify expenditures and budget cuts. The authors of recent NSS documents suggest that a positivistic methodology of weighing the probability of an emergency against its severity is possible. The 2012 National Risk Assessment (Cabinet Office, 2012: 2-3) describes its methodology as 'consulting experts in government departments and beyond'. These experts use historical and numerical analysis to assess the probability of an emergency, before employing the criteria of 'fatality', 'illness or injury', 'psychological impact', 'social disruption' and 'economic harm' (each scored from zero to five) to establish the severity of the emergency. Scenarios are then plotted along the axes of plausibility and impact, yielding a hierarchy of risk-priorities (Cabinet Office, 2012: 8).

Petersen (2013: 705-6) convincingly argues that the shakiness of such methodologies, and the ontological claims on which they rest, are clear even to proponents of 'political risk' schools. There are good reasons to argue that the NSS authors, aware of these methodological problems, 20 
sometimes use risk-security language as a rhetorical tool with which to superimpose order and objectivity on an unwieldy and contested security environment. The writing of the NSS is a highly political process, pitting different interests and perceptions against each other. A key goal for the 2010 NSS was to justify austerity cuts in defence spending. A 'national security risk assessment' provided seemingly uncontentious scientific justifications for such cuts.

It is not easy to determine how risk-security language in the NSS discourse translates into risksecurity practices, particularly in the area of political risks rather than natural hazards. The Parliamentary Joint Committee criticized the 2010 NSS for a lack of strategic policy guidance. Our analysis suggests several reasons for the discrepancy between discourse and practice. First, as described above, the rhetorical usefulness of 'political risk' analysis. Second, the fact that risk assessment exercises, especially when dealing with political risks, leave too much room for interpretation when particular crises emerge. Finally, contextual factors play a role. After a relative lull in armed conflict and upheaval around the world in the late 2000s, the period after the publication of the 2010 NSS has been highly eventful. Violent conflict has spread across Africa's Sahel belt. The Arab Spring has led to widespread turmoil, including NATO intervention in Libya and large-scale civil war in Syria. A resurgent Russia has intervened militarily in parts of Georgia (2008) and Ukraine (2014) and is challenging NATO for influence and dominance in its near region. These developments are conducive to security practices focused on present and palpable political and military threats to the sovereignty and territorial integrity of European states and their allies. This could lead to the next NSS revision, scheduled for 2015, returning to a stronger emphasis on military defence capabilities and NATO credibility, justified in the traditional language of threat-security.

From a normative point of view, can the rise of risk in the NSS discourse be viewed as progressive? As we have shown, the 'political risk analysis' approach of the 2010 NSS is only 21 
seemingly objective. Considering the many risks on the horizon and the many ways in which their probability and impact can be gauged, there is room for political preferences and value judgments in the determination of risk hierarchies and choices of responses. Unlike the political risk school, the global risk management and governmentality schools both make normative judgments. And despite being contradictory, both their perspectives are applicable to the NSS.

In line with the global risk management school, risk language has justified the expansion of security policy options, away from deterrence and war to diplomatic, cooperative and precautionary action, not just in new issue areas such as climate change, but also in the focus on preventative approaches to overseas instability. But the governmentality school points out that these same trends can have negative normative implications. Risk assessments and risk registers justify the spread of routine practices of monitoring, intervention and control. An argument can be made that JACS, the newly developed conflict assessment tool, is an example of such a controlling practice, in which fragile states become subject to enhanced monitoring by an interventionist power in the name of preventive security.

In this article, we have investigated the conceptual, practical and normative implications of the rise of risk in the NSS discourse. Regarding the conceptualisation of security, our analysis of the NSS provides evidence that the rise of risk has expanded, not radically transformed, the concept of security. Moving to security practice, risk-security language performs so many functions in the NSS that there is no simple answer to the question of what this conceptual expansion means for UK security policy. It has accompanied, and facilitated, the inclusion of environmental hazards on the security agenda, and underpins the 'resilience' and 'preparedness' responses to extreme weather events. For political dangers, risk analysis may give policy makers better tools for scanning the security horizon, but may be less useful for prescribing action in particular crisis. Finally, the normative implications are mixed: The NSS's risk-security language provides more 22 
room for non-violent, longer-term and cooperative security measures. But even preventive and non-confrontational security practices could increase levels of control and fear over a wider set of societal issues.

\section{Funding acknowledgment}

This work was supported by the Economic and Social Research Council.

\section{References}

Aradau C and Van Munster R (2007) 'Governing terrorism through risk: Taking precautions, (un)knowing the future'. European Journal of International Relations 13(1): 89-115.

Aradau C, Lobo-Guerrero L and Van Munster R (2008) 'Security, technologies of risk, and the political: Guest editors' introduction'. Security Dialogue 39(2-3): 147-154.

Beck U (1992) Risk society: Towards a new modernity. London: Sage.

Beck U (1995) Ecological politics in an age of risk. Cambridge: Polity Press.

Beck U (1999) World risk society. Cambridge: Polity Press.

Beckett M (2007) 'Margaret Beckett on climate change. The case for climate security'. Speech, Royal United Services Institute, London, 10 May 2007. Available at: http://www.rusi.org/events/past/ref:E464343E93D15A/info:public/infoID:E4643430E

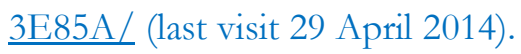

Buzan B, Wæver O and de Wilde J (1998) Security: A new framework for analysis. London: Lynne Rienner Publishers.

Cabinet Office (2008) The National Security Strategy of the United Kingdom: Security in an interdependent world. London: Crown Copyright/Cabinet Office. 
Cabinet Office (2009) National Security Strategy: Update 2009: Security for the next generation. London: Crown Copyright/Cabinet Office.

Cabinet Office (2010a) A strong Britain in an age of uncertainty. The National Security Strategy. London: Crown Copyright/Cabinet Office.

Cabinet Office (2010b) Securing Britain in an age of uncertainty. The Strategic Security and Defence Review. London: Crown Copyright/Cabinet Office.

Cabinet Office (2011) Strategic National Framework on Community Resilience. London: Crown Copyright/Cabinet Office.

Cabinet Office (2012). National risk register for civil emergencies - 2012 edition. London: Crown Copyright/Cabinet Office.

Ciuta F (2009) 'Security and the problem of context: A hermeneutical critique of securitisation theory'. Review of International Studies 35(2): 301-326.

Coker C (2002) Globalisation and insecurity in the twenty-first century: NATO and the management of risk. Adelphi Paper no. 345. London: International Institute of Strategic Studies and Oxford University Press.

Corry O (2010) 'Securitization and 'Riskization': Two grammars of security'. Working paper prepared for Standing Group on International Relations, 7th Pan-European International Relations Conference. Stockholm 9-11 September.

Corry O (2012) 'Securitisation and 'Riskification': Second-order security and the politics of climate change'. Millennium: Journal of International Studies 40(2): 235-258.

Development, Concepts and Doctrine Centre (DCDC) (2007) The DCDC Global Strategic Trends Programme 2007-2036, 3rd edition. Shrivenham: Crown Copyright/MOD.

Development, Concepts and Doctrine Centre (DCDC) (2010a) Strategic Trends Programme. Future character of conflict. Shrivenham: Crown Copyright/MOD.

Development, Concepts and Doctrine Centre (DCDC) (2010b) Strategic Trends Programme. Global strategic trends - Out to 2040, $4^{\text {th }}$ edition. Shrivenham: Crown Copyright/MOD. 
Department for International Development (DFID), Foreign Commonwealth Office (FCO) and Ministry of Defence (MOD) (2011) Building stability overseas strategy. Crown Copyright/ DFID, FCO \& MOD.

Elbe S (2008) 'Risking lives: Aids, security and three concepts of risk'. Security Dialogue 39(2-3): 177-198.

Foreign and Commonwealth Office (FCO) (2010) Preparing for global climate change: An adaptation plan for the FCO. London: FCO, Global and Economic Issues Directorate.

de Goede M (2008) 'Beyond risk: Premediation and the post-9/11 security imagination'. Security Dialogue 39(2-3): 155-176.

Heng Y-K (2006) War as risk management: Strategy and conflict in an age of globalised risks. Routledge: London.

Joint Committee on the National Security Strategy (2012). 'First review of the National Security Strategy 2010'. First Report of Session 2010-12, HL Paper 265 HC 1384. London: The Stationary Office.

Hammerstad A (2014) The rise and decline of a global security actor: UNHCR, refugee protection and security. Oxford: Oxford University Press.

Joint Doctrine \& Concept Centre (JDCC) (2003) Strategic Trends, $1^{\text {st }}$ edition. Shrivenham: Crown Copyright/ MOD.

Joseph J (2011) 'Are the French resilient? Resilience as Anglo-Saxon governmentality'. Conference paper presented at the Millennium Annual Conference 2011. London, 22-23 October.

Ministry of Defence (MOD) (1998) Strategic Defence Review. London: MOD.

Ministry of Defence (MOD) (2002a) The Strategic Defence Review. A new chapter. Volume I. London: Crown Copyright/MOD.

Ministry of Defence (MOD) (2002b) The Strategic Defence Review. A new chapter. Supporting information \& analysis. Volume II. London: Crown Copyright/MOD.

Ministry of Defence (MOD) (2003). Delivering security in a changing world. Defence White Paper. London: Crown Copyright/MOD. 
Ministry of Defence (MOD) (2008) British defence doctrine. Shrivenham: Crown Copyright/MOD.

Mythen G and Walklate S (2008) 'Terrorism, risk and international security: The perils of asking 'what if?'. Security Dialogue 39(2-3): 221-242.

Petersen, K L (2012) 'Risk: A field within Security Studies'. European Journal of International Relations 18(4): 693-717.

Rasmussen M V (2001) 'Reflexive security: NATO and international risk society'. Millennium: Journal of International Studies 30(2): 285-309.

Rasmussen M V (2004) 'It sounds like a riddle: Security Studies, the war on terror, and risk', Millennium: Journal of International Studies 33(2): 381-395.

Salter M B (2008) 'Imagining numbers: Risk, quantification and aviation security'. Security Dialogue 39(2-3): 243-266.

Trombetta M J (2008) 'Environmental security and climate change: Analysing the discourse'. Cambridge Review of International Affairs 21(4): 585-602.

Van Munster R (2005) 'Logics of security: The Copenhagen School, risk management and the war on terror'. Political Science Publication 10/2005. Odense: University of Southern Denmark.

Williams M J (2008) '(In)Security Studies, reflexive modernization and the Risk Society'. Cooperation and Conflict 43(1): 57-79.

\section{Endnotes}

\footnotetext{
${ }^{1}$ David Cameron and Nick Clegg's introduction to the 2010 National Security Strategy (Cabinet Office, 2010a: 5)

${ }^{2}$ Petersen calls this 'critical risk studies', and combines Foucauldian analysts and Critical Theory scholars in the Frankfurt school tradition. There are crucial distinctions between Critical Theory and the governmentality tradition. Since Critical Theory has produced few risk-security studies, we focus here only on the governmentality approach.
}

26

http://mc.manuscriptcentral.com/cac 
${ }^{3}$ E.g. Cabinet Office (2008: 11-12, 14-15, 18-19, 22, 29, 31, 2009: 6, 13, 40, 51-53, 88-90, 2010a: 17, 30-31, 2010b: 50, 55; DCDC (2007: 6-7, 9-11, 17, 26, 28, 34-37, 40, 2010b: 30, 61, 69, 95-99, 114-115). One exception, discussing these issues as both threat and risk is JDCC (2003).

${ }^{4}$ E.g. Cabinet Office (2008: 10-13, 2009: 11, 22-24, 75-80, 2010a: 13-14, 28-29, 2010b: 41-44, 52); DFID, FCO and MOD (2011: 10 and 27); JDCC (2003: 1.10, 1.18-1.19, 5.16, 6.3, 7.25, 7.27, 8.3, 8.10-8.11, 8.17); MOD (2002a, 2002b, 2003). DCDC (2007 and 2010) use a mixed language of threat and risk to discuss terrorism.

${ }^{5}$ Cabinet Office (2008: 12, 29, 31, 2010b: 55); DCDC (2007: 50, 2010a: 10, 2010b: 12). An exception is DCDC (2010b: 62).

${ }^{6}$ Cabinet Office (2008: 12, 29, 2010b: 55); DCDC (2010a: 8); JDCC (2003: 1.14, 8.9, 8.13); MOD (2003: 4-5, 2008, point 236).

${ }^{7}$ Cabinet Office (2009: 29, 31); DCDC (2010a: 28); JDCC (2003: 8-8); MOD (1998: chapter 3:55, 2003: 13 ).

${ }^{8}$ Cabinet Office (2008: 12); JDCC (2003: 8-10).

9 Cabinet Office (2008: 38, 2010b: 44); DFID, FCO and MOD (2011: 8); JDCC (2003: 1-10, 7-27, 8-10). An exception is DCDC (2007: 16).

${ }^{10}$ Telephone interview, Head Lessons Team, UK's Government's Stabilisation Unit, a tri-departmental unit of the FCO, DFID and MOD, 19 July 2012.

${ }^{11}$ E.g. Cabinet Office (2008: 41-43, 2010a: 10, 22, 25, 2010b: 9, 12; 29-50). DFID, FCO and MOD (2011) uses the concept of resilience to argue for strengthening fragile states to prevent conflict overseas. 